The Case of "Sonia": Psychotherapy With a Complex, Difficult Patient Grounded

E. Scherb

Pragmatic Case Studies in Psychotherapy, doi: http://dx.doi.org/10.14713/pcsp.v10i1.1844

Volume 10, Module 1, Article 1, pp. 1-29, 03-21-14 [copyright by author]

\title{
The Case of "Sonia": Psychotherapy With a Complex, Difficult Patient Grounded in the Integrated Psychotherapy Model of Héctor Fernández-Álvarez
}

\section{ELENA SCHERB ${ }^{\mathrm{a}, \mathrm{b}, \mathrm{c}}$}

a Chair, Psychology Department, Universidad Argentina De La Empresa

b Correspondence regarding this article should be addressed to Elena Scherb, Professor Doctor, Lima 717 Capital Federal, Buenos Aires, Capital Federal, 1427 Argentina

Email: elenascherb@gmail.com

c I want to acknowledge my deep gratitude to the AIGLE center in Buenos Aires generally, and to Professor FernándezÁlvarez specifically, for providing an inspiring training context in which research, training, and clinical practice were conducted at an international level, for all kinds of psychological problems in Argentina.

I also want to acknowledge the wise and insightful editorial help from the PCSP editor and his graduate student editorial staff at the Graduate School of Applied and Professional Psychology of Rutgers University, including Tanya Farber, Steven Clark, Brendan Graziano, and William Buerger.

\begin{abstract}
Sonia was part of a clinical, naturalistic, and longitudinal research project I developed that began in 1998, with patients who consulted at the well-known AIGLE center in Buenos Aires, Argentina. In the project I selected patients with severe and complex psychological symptoms for whom previous treatments were reported by the patients to have been ineffective. The goal of the project was to employ Dr. Héctor Fernández-Álvarez's Integrative Psychotherapy Model to design a new treatment approach involving combined strategies that could successfully work with such individuals. At the time of intake, Sonia was a 44-year-old, divorced, morbidly obese woman living with her 18-yearold mildly retarded son in an apartment purchased for her by her affluent parents. When Sonia came for treatment, she could not manage her son or her own basic needs and finances and had frequent angry outbursts with her family members. She was diagnosed as having bipolar disorder or cyclothymia, trichotillomania, borderline personality disorder, borderline intellectual functioning, and was on medication for these conditions. This case study describes 10 years of treatment, including over 900 sessions, working on the development of Sonia's coping and interpersonal skills and on restructuring her most basic cognitions about herself and her relationships to others, particularly her family members. During the 10 years, the therapy was gradually reduced in intensity as Sonia made gradual but dramatic changes in her self-concept, her obesity, her relationship to her family, and her ability to work and independently manage her life. While because of her long history of previous treatments, Sonia did not consent to take any standardized assessment measures, she did agree to a collaboratively developed, individualized, 27-item List of Problems and Behaviors Questionnaire (LOPBQ). With a scoring range of 0 ("problem not solved at all") to 5 (problem "totally solved") on each item, Sonia went from an average item score of .33 to one of 4.19 over the course of the first 8 years; that is, from a score of $6.7 \%$ of a maximum score to $83.8 \%$ of a maximum score. The process by which this impressive change took place is detailed.
\end{abstract} Key words: borderline personality disorder; bipolar disorder; severe and persistent mental disorder; morbid obesity; Fernández-Álvarez's Integrated Psychotherapy Model; skill training; case study; clinical case study 
The Case of "Sonia": Psychotherapy With a Complex, Difficult Patient Grounded

E. Scherb

Pragmatic Case Studies in Psychotherapy, http://pcsp.libraries.rutgers.edu

Volume 10, Module 1, Article 1, pp. 1-29, 03-21-14 [copyright by author]

\section{CASE CONTEXT AND METHOD}

Sonia, the case described below, was admitted to and began treatment in the AIGLE Foundation (http://www.aigle.org.ar/), a clinical center that provides care, prevention, and research in mental health and is headquartered in Buenos Aires, Argentina (Fernández- Álvarez, Garcia, \& Scherb, 1998). AIGLE began its activities over 35 years ago and currently has branches in other cities throughout the country. The Foundation uses psychotherapy, drug therapy, social work and combined treatments to treat persons from a range of socioeconomic circumstances who present with a wide range of mental disorders.

Working in AIGLE in 1998, I observed that new treatments grounded in Dr. Héctor Fernández-Álvarez's Integrated Psychotherapy Model were far more effective than previous treatments for a wide range of psychological problems treated at AIGLE. This observation inspired me to start a research project to work with AIGLE patients with the following characteristics: severe and complex psychological symptoms; multiple problems in functioning; and more than three previous intensive treatments that were described by the patients as ineffective, typically including past hospitalizations, intensive psychotherapy, and/or pharmacology. I chose such cases in part because they incurred the highest costs in terms of patient suffering and the cost of treatment. This study became my doctoral dissertation (Scherb, 2007a) and has been described in a variety of other contexts (Scherb, 2003, 2007b, 2011, 2012).

Since concluding my formal study with the dissertation, I have continued the work with clients like Sonia in a private practice. I perform this work with the collaboration of the AIGLE Center for assessment with standardized measures, and, currently, with an independent group of therapists — all of them trained in the Dr. Fernández- Álvarez Integrated Model — who join me in peer supervision with our cases, creating a collaborative network.

\section{THE CLIENT}

At the time of intake, Sonia was a 44-year-old, morbidly obese woman living with her 18-year-old son in an apartment purchased for her by her parents. Sonia had divorced the father of her only child 15 years before coming to the clinic. Her son suffered from mild mental retardation (MR) and had been receiving assistance from special educational institutions. When Sonia came for treatment, the family was searching for institutions that would support an adult with MR. Sonia was unable to manage her son, her own basic needs, and her financial situation. While relying on her parents, she frequently was in conflict with them.

\section{GUIDING CONCEPTION WITH RESEARCH AND CLINICAL EXPERIENCE SUPPORT}

\section{Overview of the Integrated Psychotherapy Model}

The therapy employed was based on Dr. Héctor Fernández- Álvarez's Integrated Psychotherapy Model, especially as set forth in his 2001 book, Fundamentals of an Integrated Model of Psychotherapy (Fernández-Álvarez, 2001). 
The Case of "Sonia": Psychotherapy With a Complex, Difficult Patient Grounded

E. Scherb

Pragmatic Case Studies in Psychotherapy, http://pcsp.libraries.rutgers.edu

Volume 10, Module 1, Article 1, pp. 1-29, 03-21-14 [copyright by author]

The Integrated Model is founded upon the idea that psychotherapy is, at its root, a means of promoting change. Within this model, change promotion occurs within boundaries, which are determined by schemas. Schemas are in turn determined in accordance with biological, psychological, and social perspectives. Therefore, interventions in this model are executed in the context of a biopsychosocial universe and framed within the patients' schemas. In this vein, resistance is understood as a function of the protection of self-identity. In order to help patients achieve change, the therapist seeks to change dysfunctional belief systems, utilizing resistance as a guide for understanding underlying conflicts, without confrontation. In late stages of treatment, it is common that patients become ready to confront resistance without putting the attained goals at stake.

These schemas are belief systems that are hierarchically organized and represent the way in which individuals see the world and themselves within it. Schemas constitute the architecture of the self and individual strength to face world challenges. Development represents a challenge in every stage of growth, which in turn demands adequate adaptation of the schemas to everchanging reality. Challenges can be solved via a synthesis between opposites. The more functional the schemas are, the better we can respond to reality. The organization of schemas resembles the structure of a building, in which each stage is built upon the previous one. Development becomes stuck when there is incongruence in the development of meaning, causing the whole structure to become vulnerable. However, unlike buildings, the more complex structures can be also modified and adapted to reframe the meaning of the previous structures retrospectively. Psychotherapy is aimed at identifying dysfunctional schemas and restructuring them.

Within the Integrated Model, treatment involves an adequate assessment of the level of dysfunction of schemas and the application of a specific intervention. The presence of relatively simple and non-severe problems would suggest interventions at a relatively simple level, such as cognitive-behavioral techniques to treat uncomplicated phobias. This treatment would be brief and should mostly prove successful. Cognitive therapy with depression has overwhelmingly shown positive results, especially when the problem is relatively straightforward. When problems are less clearly defined and/or there are comorbid symptoms present, additional clinical considerations within the model should be taken into account.

\section{Specific Strategies for Dealing with Severe and Persistent Psychopathology}

Overall, the Integrated Model involves the integration of behavioral, cognitive, and systemic concepts and strategies. Specifically, as applied to individuals with severe and persistent psychiatric disorders, the strategies can be summarized as follows:

1. Identify the appropriate dysfunctional schema and tailor interventions according to level of dysfunction. This means starting from the level at which change should be easy to achieve, which includes enhancement of the patient's self-efficacy (through validation, support, empathy, skill training, etc.) in this first moment to help increase motivation. 
The Case of "Sonia": Psychotherapy With a Complex, Difficult Patient Grounded

E. Scherb

Pragmatic Case Studies in Psychotherapy, http://pcsp.libraries.rutgers.edu

Volume 10, Module 1, Article 1, pp. 1-29, 03-21-14 [copyright by author]

2. Focus on dysfunctional interactional patterns to identify negative interactional vicious cycles (Wachtel, 1997) that can maintain the dysfunction. Gradually, these issues need to be addressed in the context of a strong therapeutic alliance.

3. Change the treatment setting if needed (for example, some undergo brief periods of inpatient treatment, while others require occasional visits to the patient's place of work).

4. Change modalities if needed, and implement this in a coordinated and sequential manner.

5. Include conjoint and/or family targeted sessions when necessary. These sessions need to be designed in favour of the client and should not focus on guilt or blame.

6. Integrate contextual variables (institutions, community resources) into the treatment through targeted consultation when necessary, always supporting the client's social involvement.

7. Promote only gradual changes, reassessing treatment goals continually.

8. Include patients' and significant others' resources for change (through participation, assessment, and re-assessment).

9. Provide positive reinforcement, validating the patient's personal experiencing at all times.

10. Reverse the patient's victim attitude and support the gradual assumption of responsibility.

11. Depathologize psychiatric patients who have undergone traditional psychiatric treatments for many years, namely hospitalization, heavy medication, and/or ECT for long periods of time. These patients often become stigmatized by their significant others and by society in general.

12. Create a treatment team in response to the special challenge of these difficult patients (Linehan, 1993). (Note that in Sonia's case, the team was composed of a psychologist psychotherapist [the author], a psychiatrist, an occupational therapist, and a social worker.)

\section{ASSESSMENT OF THE PATIENT'S PROBLEMS, GOALS, STRENGTHS, AND HISTORY}

\section{Presenting Situation}

As mentioned above, at the time of intake, Sonia was a morbidly obese, 44-year-old woman living with her 18-year-old son in an apartment purchased for her by her parents. She had divorced the father of her only child 15 years before coming to the clinic. Her son suffered from mild mental retardation (MR) and had been receiving assistance from special educational institutions. When Sonia came for treatment, the family was searching for institutions that would support adults with MR.

Sonia was unable to manage her son, her own basic needs, and her financial situation. While relying on her parents (as well as others) for help, she frequently was in conflict with 
The Case of "Sonia": Psychotherapy With a Complex, Difficult Patient Grounded

E. Scherb

Pragmatic Case Studies in Psychotherapy, http://pcsp.libraries.rutgers.edu

Volume 10, Module 1, Article 1, pp. 1-29, 03-21-14 [copyright by author]

them. Her relationships with her parents proved strained and dysfunctional, with both parties expressing resentment. Sonia often experienced conflict with her family. She had been repeatedly hospitalized for these and other issues, which included depressive symptoms and violent outbursts. She was referred to me by one of her medical doctors because she refused to be hospitalized for the third time in three years.

\section{Sonia and Her Child}

In Argentina, at the time of the Sonia's treatment, the mental health system had only one type of response for severely disturbed patients like Sonia: psychiatric consultation and detention in a mental health inpatient facility. For many years, Sonia oscillated between various psychiatrists and institutions with no apparent results. In relation to her son's difficulties, schools for children with special needs are relatively easy to find. However, after the child reaches the age of 18, the Argentine system has no clear options. Help at later stages of life relies upon private health companies to offer supportive care for the mentally retarded.

At some point in Sonia's treatment, there was a new mental health law that was promoted, and institutional options for the mentally retarded started to be an option within the private health companies. Although the new mental health law implied the necessity of alternative treatments for the mentally ill other than the previous psychiatric detention system, the only options available for Sonia's child during the time of treatment were at a private level.

\section{Relationships with Family Members and Helpers}

Sonia described her relationships with her parents and brother as poor, characterized by constant insults and fighting. She conveyed a sense of resentment toward these family members, maintaining that her relatives did not deserve to have a good relationship with her, as they had always rejected her for being obese, bearing a child with mental retardation, and divorcing her ex-husband.

At intake, Sonia's parents were providing her with total financial assistance as well as daily life support. Her mother visited Sonia at her apartment daily, bringing small amounts of money and giving instructions to a social worker, therapeutic helper, and a maid, who also spent time with and helped Sonia. At the beginning of treatment, the social worker would spend four hours a day; the therapeutic helper two hours, three times a week; and the maid, six hours a day. In addition, my psychotherapy sessions with Sonia took place three times a week, and the psychiatrist's medication management session was held every two weeks. This overall arrangement lasted for the first six months of treatment.

Since Sonia could not stick to her budget, her parents and brother had decided to monitor her spending, checking in every two or three days. Sonia perceived this financial supervision as an example of her mother's overprotective behavior and occasionally reacted by yelling insults at her mother. When her mother would withdraw, Sonia would ultimately need to ask for help again, effectively restarting the vicious circle. Sonia reported having very poor relationships with those close to her at the time of intake, including her brother, sister-in-law, maid, and social 
The Case of "Sonia": Psychotherapy With a Complex, Difficult Patient Grounded

E. Scherb

Pragmatic Case Studies in Psychotherapy, http://pcsp.libraries.rutgers.edu

Volume 10, Module 1, Article 1, pp. 1-29, 03-21-14 [copyright by author]

worker. Beyond these relationships, she had one or two people she called friends, but whom she rarely saw.

Sonia's father overtly rejected her because of her obesity. He refused to participate in the initial family sessions because he "could not bear to look at [his] daughter in that shape." In Sonia's family, only her mother was still trying to help her, although not without ambivalence. Sonia is the eldest of three siblings in a family of renowned doctors. It seemed that her family was pressing for Sonia's hospitalization as a way of putting all these problems out of sight and out of the way. In their minds, her hospitalization would allow each of them to have a life. This belief overtly or covertly was expressed throughout treatment. Every time Sonia seemed to regress, they would suggest hospitalization in spite of the clear benefits of continuing this new treatment at the AIGLE clinic, and later on, in private therapy. This continuous assessment of the expectations, motivation, and resources of Sonia's significant others served as part of the therapeutic strategy. From the beginning, Sonia insisted on seeking help in a way that avoided hospitalization. This motivation was a key factor in relation to outcome.

\section{Dyadic Interpersonal Anxiety and Negative Symptom Reinforcement}

Sonia and her mother were seemingly trapped in a negative symbiotic relationship, and over the years Sonia had progressively withdrawn from other social relations. This social deprivation created in Sonia feelings of loneliness, frustration, abandonment, and self-perceived failure, in response to which Sonia compensated by overeating. This overeating was motivated by a lack of reinforcers in her life, but had the negative result of contributing to her obesity, thereby confirming her negative body image and the invalidation provided by significant others, such as her mother.

\section{DSM-IV Diagnoses}

Axis I

- 296.6. Bipolar I and/or 301.13. Cyclothymia.

When Sonia was referred to me by her medical doctor, she was diagnosed by the last psychiatrist with Bipolar Disorder, and was medicated accordingly. Nevertheless, after several interviews, the psychiatrist on my team decided to medicate Sonia with Actinerval (carbamazepine), which is indicated for resistant hypomania. The psychiatrist prescribed this medication plan because it was very useful in combination with the treatment strategy. As the treatment developed over time, Sonia's dose was gradually reduced. Therefore, retrospectively, we thought that Cyclothymia would be a more accurate description of Sonia's pathology.

- 312.39. Trichotillomania

$\underline{\text { Axis II }}$

- 301.83. Borderline Personality Disorder

- V62.89. Borderline Intellectual Functioning 
The Case of "Sonia": Psychotherapy With a Complex, Difficult Patient Grounded

E. Scherb

Pragmatic Case Studies in Psychotherapy, http://pcsp.libraries.rutgers.edu

Volume 10, Module 1, Article 1, pp. 1-29, 03-21-14 [copyright by author]

$\underline{\text { Axis III }}$

- 278. Obesity

Axis IV

- V61.20. Parent-Child Relational Problems

- V61.9. Relational Problem Related to a Mental Disorder or General Medical Condition

- Anger Control Problems

Axis V: Global Assessment of Functioning, 40

\section{Medication}

When I first saw Sonia, she was on a heavy antidepressant regimen. Together with the psychiatrist in the team, she slowly transitioned the pharmacotherapy to carbamazepine, as I explained above. In the final stage, Sonia was treated with a maintenance dose. She was never under lithium during my treatment, although she had been treated for many years with lithium during previous treatments. Sonia had always been compliant with the medications and it was therefore easy to assess the medication effects at all times. In the final stages of my treatment, she started with Orlistat for obesity, but she was not compliant with this medication.

\section{A Picture of the First Interviews}

When I first met Sonia, she was unable to manage her daily routine in the house. Often crying in desperation, she was aggressive and sometimes violent, primarily with her parents and brother. However, at times she was also aggressive with others including neighbors, taxi-drivers, shopkeepers, and occasionally her son. When this happened, she would shout things like, "Why was I left alone with this child?" "Why is no one helping me out?" and "Where is his father?" These outbursts occurred in front of the child, who would become very nervous and scream along with his mother.

Sonia would phone her parents literally hundreds of times in the day and in the night, frequently bursting into tears. She would stand in front of her mother's home, shouting and yelling about how her family had abandoned her. During her last hospitalization, before I began my outpatient treatment, Sonia had hit a nurse and thrown an ashtray against the window in the psychiatrist's office. Many years prior to my intake Sonia had abandoned her last job and her educational studies. She did not cook or clean her house by herself. She relied upon the social worker, who helped her with her son; the maid, who cleaned the house; and her mother, who would try, unsuccessfully, to soothe her. Sonia would stay in bed all day crying. Her main activities consisted of her violent discussions with her parents and even ordinary people in the streets.

Because of Sonia's long history of generally negative experiences with previous treatments, she did not consent to take any standardized assessment measure. However, she willingly filled out a List of Problems questionnaire and agreed to audio and video recording of 
The Case of "Sonia": Psychotherapy With a Complex, Difficult Patient Grounded

E. Scherb

Pragmatic Case Studies in Psychotherapy, http://pcsp.libraries.rutgers.edu

Volume 10, Module 1, Article 1, pp. 1-29, 03-21-14 [copyright by author]

the sessions. Her rejection of standardized measures in treatment hinted at one of her primary strengths - her assertiveness_-which was unveiled later in treatment.

\section{FORMULATION AND TREATMENT PLAN}

\section{Formulation (based on Persons' [2008] Model)}

\section{Presenting Context, Problems, and Symptoms}

Sonia had been repeatedly hospitalized for a total of 5 times and treated for depressive symptoms and violent outbursts. She was referred to me by one of her medical doctors because she had refused to be hospitalized for the third time in three years.

\section{$\underline{\text { Problem List }}$}

1) Sonia was unable to adequately care for her adult son.

2) Sonia resented her parents for being overbearing, but would also feel abandoned by them and plead for help.

3) Sonia would react explosively to frustrating situations.

4) Sonia had trouble both staying out of and staying in the psychiatric hospital.

5) Sonia suffered from low self-esteem, which centered on her obesity and her low achievement in relation to significant others.

6) Sonia was unable to manage basic life tasks and finances.

7) Sonia was unable to manage her own healthcare and social support.

8) Sonia had very few friends and little contact with the friends that she had.

9) Sonia demonstrated self-injury behaviors. Specifically, engaging in hair pulling (Tricotillomania) caused her skull to go bald in many areas.

10) Sonia suffered from frequent depressive symptoms.

11) Sonia could not control spending. For instance, in one week she would buy 50 small dolls and run out of money three days after receiving her weekly allowance.

12) Sonia showed bizarre and abusive behavior towards her immediate family, her relatives, and with her continuing boyfriend (with whom she had abusive relationship issues, including bizarre sexual behavior).

13) Sonia engaged in over-eating, contributing to her obesity. (Note that she did not show any chemical dependence.) 
The Case of "Sonia": Psychotherapy With a Complex, Difficult Patient Grounded

E. Scherb

Pragmatic Case Studies in Psychotherapy, http://pcsp.libraries.rutgers.edu

Volume 10, Module 1, Article 1, pp. 1-29, 03-21-14 [copyright by author]

\section{Mechanisms Currently Maintaining the Problems}

Sonia's Bipolar Disorder and Borderline Personality Disorder reflected a general mood disorder and emotion regulation disturbance, which can be partly explained by her biological vulnerability in this area. Sonia also lacked the basic social skills required to engage with others to have her needs met. Due to this lack of skills, Sonia resorted to frantic and primitive attempts to influence others to help her in meeting her needs. Sonia also had a core personal belief that her obesity meant that she was worthless and unlovable.

\section{Origins of Mechanisms}

As a child of prominent physicians, expectations for Sonia were high from early childhood. Sonia differed from her parents and other siblings in her emotionally sensitive disposition and modest cognitive resources. Sonia's parents frequently punished displays of Sonia's emotions and would dismiss Sonia's pleas to have her needs met. This rejection would be followed by her mother' overprotective behaviors, which reinforced Sonia's inability to selfregulate. For example, when Sonia was a toddler, her mother felt that she could not cope with her child's difficulties alone. Sonia's father was not supportive in terms of affection. Therefore, Sonia's mother sent her to live with a relative, who was also a teacher, and visited her every weekend. This had been a recommendation of the doctors at that time, and also served to prepare Sonia for school. Although Sonia has good memories of her stay with this teacher, she also recalls that she burst into tears and violent behavior every time her mother visited her. In the end, this lasted only a few months and Sonia was brought home again. Nevertheless, Sonia viewed this time with her relative as being very helpful, as it allowed her to prepare herself for school and finally see evidence of her own success. On the other hand, her mother recognized that she was unable to handle Sonia as a child, although she couldn't identify what the problem was. Her father, on the other hand, never acknowledged that something was wrong in rearing his child.

As a result of this invalidating environment, Sonia would attempt even more extreme expressions of affect until she would elicit the desired response from her parents. Sonia's mother would punish and then overprotect her, a vicious circle generated out of irritation and then guilt, while her father was an absent figure in terms of affection. As a result, Sonia's extreme expressions of emotion were reinforced throughout her development as a child. As this method of influencing the world was effective for Sonia, she lacked the opportunity to learn methods of self-regulation and appropriate social skills in order to care for herself. Nevertheless, she went through childhood and adolescence with relative success, until the moment in which she was to become an adult woman. She married impulsively at a very young age, without her parents' consent, and became the mother of a mildly mentally retarded son. Although her family supported her financially, her life situation was seen as an embarrassing failure by both Sonia and her family, which in turn led to ambivalence, rejection, abandonment, remorse, and feelings of impotence and helplessness on both sides. This situation triggered Sonia's dysfunctional nuclear schemas of being worthless and deserving to be shunned by her family, which fueled Sonia's dysfunctional needs for fulfillment through food, finally leading her to a state of morbid obesity. Sonia's belief about being worthless and unlovable was confirmed by excessive criticism of her weight by her father. 
The Case of "Sonia": Psychotherapy With a Complex, Difficult Patient Grounded

E. Scherb

Pragmatic Case Studies in Psychotherapy, http://pcsp.libraries.rutgers.edu

Volume 10, Module 1, Article 1, pp. 1-29, 03-21-14 [copyright by author]

\section{The Case Formulation}

As a result of hospitalizations and varying support from her loved ones, Sonia experienced life as very unstable and perceived others as undependable. Sonia's support system vacillated between being characterized by invasive over-management and loss of freedom (e.g., with hospitalization or with management of her pension) and abandonment (e.g., when her family would become fed up and leave her alone). Often Sonia's reaction to the perceived abandonment would be so extreme that her family would respond in an equally extreme way, which often led to pressuring her to be hospitalized.

During times of crisis, the family would react by taking over Sonia's finances, and managing the care of both Sonia and her son. At these times, Sonia would react with explosive anger. As a result, Sonia and her family would engage in conflicts that would often cause the family to withdraw. As Sonia's sources of support began to withdraw, she would then use extreme emotional reactions as a means of obtaining additional support. In this way, Sonia's interaction with her family and their responses to her would fuel a negative cycle of invasive approach and withdrawal. Whether Sonia was anxious about the micro-management of her life or the perceived abandonment on the part of her family, her violent emotional displays such as screaming or threatening her family would mitigate her anxiety and also change the situation, thereby negatively reinforcing her violent displays. However, due to the inconsistency of her support system, these displays were also negatively reinforced on an intermittent schedule. This made the problem behaviors very resistant to extinction, and any "extinction burst" would often result in even more extreme attempts to manage her environment.

Self-injury was involved in a covert manner. For example, Sonia dated a man who was abusive towards her, belittling her, being physically aggressive, and performing unprotected sex. This man (who had a mental health problem himself) had a place to live, but had also been unemployed for more than 15 years. It is noteworthy that when she met him on the street years ago, he was actively working as a bus driver, but very soon after lost this job and never thereafter earned an income. At times, he would borrow money from her for cigarettes, food, and so forth.

During all these years, Sonia had progressively withdrawn from social contact, which increased her feelings of loneliness, frustration, abandonment, and perceived failures.

Sonia's eating was motivated by a lack of reinforcers in her life, but had negative results in contributing to her obesity, therefore confirming her negative body image.

Because Sonia had never learned appropriate interpersonal skills, it was difficult for her to come up with alternative help-seeking behaviors when in distress. As a result, Sonia had very few friends, whom she saw only occasionally. In addition, her parents overtly criticized her obesity and urged her to lose weight. Interpersonal failures and criticism on the part of her family further confirmed Sonia's core belief that she was in fact worthless and unlovable. It was difficult, therefore, to convince Sonia to engage in change because she would often perceive the suggestion that she change as rejection. Therefore, work with Sonia needed to take all of these 
The Case of "Sonia": Psychotherapy With a Complex, Difficult Patient Grounded

E. Scherb

Pragmatic Case Studies in Psychotherapy, http://pcsp.libraries.rutgers.edu

Volume 10, Module 1, Article 1, pp. 1-29, 03-21-14 [copyright by author]

factors into account in order to provide her with a new experience of validation within the context of a change-oriented therapy.

\section{Treatment Plan}

The treatment was designed as a combination of intensive psychotherapy, psychotropic medication (consisting of a carbamazepine), family therapy, and case management, which included a referral for her son to an appropriate supportive institution. The treatment team included a psychologist psychotherapist (the author), a psychiatrist, and an independent assessment team, with psychotherapy sessions being conducted in a variety of settings. These included private consultation offices, her parents' house, Sonia's apartment, her son's school, and, in the last stages of treatment, her workplace. The therapy sessions were held in these locations to help Sonia engage in new behaviors and coping strategies in the environments in which they were needed. For example, several times the therapist went with Sonia to her son's institution to help her cope with her son, and to talk with the people at the institution within the context of a very strong working alliance with her therapist. Overall, cognitive restructuring and training in interpersonal skills (derived from Fernández-Álvarez Integrated Model) would be used to address dysfunctional interactional patterns.

Sonia's treatment was conceived from the beginning as long-term. This was the case not only because of the complex nature of her problems, her comorbid conditions, and the multiple problems she presented, but also because of her long history of previous treatments with no clear results and associated stigmatization. From the beginning, it was clear that the first step should be to find some aspect in which Sonia could believe in herself (the beginning of self-esteem), from which to start building herself again with the help of the therapy process. At the same time, we had to work towards changing her family's negative perception towards her and the poor expectations they had of her outcome.

It was apparent from the first day that there was a negative communication pattern between Sonia and her significant others. In this pattern, Sonia's emotional dysregulation caused her family members to reject her. This rejection further fueled her dysregulation, thereby exacerbating her problematic behaviors and leading into her violent disruptions that ended in her being labeled as the "mentally ill person."

From the beginning of treatment, the focus was to change this dysfunctional relational pattern by changing Sonia's behavior. In order to achieve this, it was necessary to address her dysfunctional beliefs about herself as being worthless and not deserving any love from anybody. At the same time, it was necessary to help her family to gain a different perspective towards Sonia's problems and way of being. Because of the rigidity and severity of the symptoms and the long periods of previous treatments, these changes had to be addressed gradually. Any small change would be useful. The key to making progress in these first steps was to build on any small gain in order to reverse Sonia's invalidated self.

The first two techniques utilized in treatment were to build a strong, positive but directive therapeutic relationship in which Sonia could trust the therapist, and to address family members 
The Case of "Sonia": Psychotherapy With a Complex, Difficult Patient Grounded

E. Scherb

Pragmatic Case Studies in Psychotherapy, http://pcsp.libraries.rutgers.edu

Volume 10, Module 1, Article 1, pp. 1-29, 03-21-14 [copyright by author]

in a psycho-educational manner, such as to teach them other possible ways to interact with Sonia. The ultimate goal of these interventions was to help reverse Sonia's invalidating context and victimized attitude and to help her become more responsible, which would lead her to become more independent. This would then increase her sense of self-worth and self-esteem, changing the vicious circle into a virtuous one. Because of the frequent regressions at this initial period, it was necessary to perform a continuous assessment of progress throughout this stage of the treatment. This was especially useful for Sonia, because it gave her positive feedback regarding her efforts. Every small change in behavior and in her ability to relate to others was conceived as an individual achievement, and an approximation towards her final goal.

In this type of treatment, the tasks between sessions have a relevant role. In order to accomplish this goal, Sonia had a therapeutic coach who helped her with these tasks during the beginning stages of treatment.

In sum, treatment consisted of addressing family issues, engaging in cognitive restructuring, eliciting behavior changes, decreasing emotional dysregulation, addressing thought distortion, and confronting multiple problems of varying levels of severity. To do these tasks involved individual sessions with a therapeutic coach and a psychiatrist, and intensive individual and family sessions with the psychotherapist (the author), all coordinated by the psychotherapist. The intensive psychotherapy was the core structure of the treatment, although the amount of intervention was regulated in relation to the successive gains. If Sonia demonstrated that she was able to perform one task between sessions while being accompanied by the therapeutic coach (for example, being able to attend a computer skills class without abandoning or fighting with her teacher), she would then be allowed to do it by herself. Also, Sonia received rewards (e.g., going on a vacation or buying something her parents had previously denied her) for exhibiting prosocial behaviors.

In the beginning, the therapeutic coach always provided instruction and guidance to Sonia whenever she had exaggerated reactions or thought distortions. After the task, we would meet together in the session with the therapeutic coach and discuss what happened. Sessions with Sonia's mother and occasionally her brother were also included, but limited to a specific goal, always trying to help them find a better way to relate to Sonia, trying not to engage in blaming or criticizing herself or others, unless there was a clear positive goal to reach. It was always made clear that these family sessions were designed to help Sonia, not to blame her.

In the more advanced phases of treatment, the rewards Sonia obtained were more related to her personal satisfaction in gaining a job or a new friend.

The treatment strategy was to offer Sonia specific intensive emotional support that would gradually be reduced as she improved, and would later be substituted with more challenging and directive types of interventions. For example, in an effort to help Sonia gain control over her spending behavior, we first helped her complete her weekly shopping list and calculate the money she needed to spend every week. Over time, this became a monthly activity, so Sonia could gain control over her spending and start budgeting her own money. When she would lose control over her spending once more, we would not go back to the beginning stage of treatment 
The Case of "Sonia": Psychotherapy With a Complex, Difficult Patient Grounded

E. Scherb

Pragmatic Case Studies in Psychotherapy, http://pcsp.libraries.rutgers.edu

Volume 10, Module 1, Article 1, pp. 1-29, 03-21-14 [copyright by author]

(weekly shopping lists), but rather to the last gain (monthly shopping lists) and move forward from there. Later in treatment, I would confront Sonia's cognitive distortions using daily examples and cognitive restructuring techniques. At the same time, emotion-vulnerabilitycontrol-training would be employed (using Marsha Linehan's [1993] techniques) to help Sonia cope with emotional instability. As cognitive therapy for depression continued, treatment for family members was conducted from a psychoeducational perspective.

\section{COURSE OF THERAPY (SEE OUTLINE IN TABLE 1)}

\section{First Phase, Year 1: Working with the Family and Sonia's Other Social Support System}

\section{Developing Appropriate Family Expectations}

Because of the complexity and severity of this case and Sonia's extensive psychiatric history, the first intervention was implemented with the family. Her parents, brother, sister-inlaw, and son were invited to three interviews. The focus of these sessions was to assess the expectations of the family, explain the type of treatment that would be carried out, inform Sonia and her family of the risks and potential gains of treatment, and obtain informed consent for the treatment strategies proposed. This consent was a pre-condition to treatment.

Although the family was exhausted and disappointed with the outcome of Sonia's past therapy, I communicated to them that treatment success was more likely if they expressed their support for Sonia starting treatment in this new modality. In these first sessions, despite the fact that the family was angry, exhausted, and frustrated because of the burden Sonia represented, they also wanted to believe in a possible change. I told them that in my view this is why they came, that as human beings we always have hope, and that this small hope was all that we needed to get started.

In one of the first sessions, Sonia's brother asked if his sister would be cured. The answer was that there was no guarantee, but that we believed it was worth trying. This answer helped to reduce their anxiety, because many other times they had been met with another type of answer that is more familiar in the medical context, where the question is frequently framed dichotomously as either "to cure or not to cure." These first sessions were more psychoeducational in style, explaining to the family the nature of Sonia's illness and why we believed it would be worthwhile to give this new treatment a chance. Analogies with other types of treatments were utilized, in which the targeted diseases could be chronic, but the quality of life within the illness could still be improved. The family was thus engaged to give it a try, not for a cure, but for a better quality of life with the illness.

Another important aspect of the intervention was that we offered continuous assessment of the treatment process. This was done through periodic sessions with members of the family, in which we would show how change was achieved in a particular area. For example, after the first phase of treatment, we showed them how much the intrusive and aggressive telephone calls had reduced, or, later in treatment, how effectively Sonia had learned to manage her finances. These types of sessions were scheduled directly with the family members. Sometimes Sonia 
The Case of "Sonia": Psychotherapy With a Complex, Difficult Patient Grounded

E. Scherb

Pragmatic Case Studies in Psychotherapy, http://pcsp.libraries.rutgers.edu

Volume 10, Module 1, Article 1, pp. 1-29, 03-21-14 [copyright by author]

would be present and sometimes she would not, but she would always be informed. In the beginning, the family members often expressed a defeatist attitude, but in time this slowly transformed into a collaborative one. In this way, we also helped the family to adjust their level of expectations towards gains, thus learning to accept and understand how to better deal with Sonia's problem and its impact on their daily lives.

Within the first three sessions, a contract was forged in which the family would give this new treatment a try, and we would provide feedback to them on the treatment progress. I first described to the family the structure of the treatment. For example, I detailed who would and would not be present in the family sessions, if Sonia's mother should come in, and how many sessions a week I believed we needed. I explained that I would be responsible for explaining the strategies and would show the family in what way these strategies were designed to be beneficial. Because this was a private treatment, the family agreed to pay out-of-pocket for the services rendered.

It was not easy to build a cooperative bond with the family. For example, although in these first sessions everyone was invited, Sonia's father would not come. I concluded that requiring him to come might result in the therapy coming to a halt, and therefore decided to proceed without him.

In the second session, Sonia suddenly burst into tears and shouted that she had always been rejected, treated as if she were not part of the family, and sent to the psychiatric hospital like a dog. I asked her to leave and to come back when she could maintain a conversation without shouting or screaming. She stepped out of the room, phoned the therapist and told her that she preferred not to be in the room but nevertheless she wanted to cooperate with treatment. We considered whether or not to resume the session without Sonia in order to consistently enforce the expectation that she not shout and scream. We decided to resume it. She was not present in the next meeting.

During the next two weeks, I had intensive individual psychotherapy sessions with Sonia, during which, among other issues, I made clear to Sonia her responsibility to participate in the initial contract of the treatment together with her family. In addition, I promised her that after finalizing the contract, she would not be forced to participate in family meetings if she did not want to. This helped her go through this stage, because in previous treatments she had very bad memories of therapists forcing her to attend meetings with her family in which she felt she was the one who would be was blamed. It was only in the very last stages in treatment that Sonia was able to participate actively in a family session without yelling, insulting, or blaming the other family members. In the years after the contract to begin the treatment was completed, the family sessions were held mostly with only the mother (although occasionally the brother and sister-inlaw did attend). This lasted until the final phase of treatment during which we could hold family sessions with everyone.

Sonia's father, who did not attend the initial full family meeting, was called upon to meet with his wife and me. He told us that he rejected his daughter, that he could not bear to see her the way she was, and that this would not change. Therefore, he did not participate in these initial 
The Case of "Sonia": Psychotherapy With a Complex, Difficult Patient Grounded

E. Scherb

Pragmatic Case Studies in Psychotherapy, http://pcsp.libraries.rutgers.edu

Volume 10, Module 1, Article 1, pp. 1-29, 03-21-14 [copyright by author]

family sessions and only came in 5 years later. Finally, the family agreed to start this new treatment, deciding that it was their best option.

This initial collaboration with the patient's family was essential to the first and second phases of this treatment. In this first phase, we worked with a team that included a psychiatrist, a supporting mental health therapeutic coach, and a social worker. This level of support was deemed necessary for the treatment given Sonia's high level of impulsivity and relative lack of behavioral and emotional control.

\section{Creating Sonia's Other Social Support System}

In order to achieve gradual withdrawal of such additional supports, the therapist, following a behavior therapy strategy, worked with Sonia concerning the rewards coming to her every time she could manage in a more adaptive manner. As described above, I selected two simple behaviors that she could start to manage by herself. Although at the beginning she complained that "nobody helps me," it became very evident to her that gaining responsibility allowed her to gain freedom, and this ultimately made her feel better. We not only had to struggle with her tendency towards passivity and victimization, but also, more importantly, with her family's tendency to overprotect and underestimate her. The strategy was that the better she could manage her spending (or any other behavior), the more the therapist would instruct her mother to let go, thus enhancing not only her autonomy but also her dignity and self-esteem. This was essentially a token-economy-like behavioral technique, as applied to self-responsibility and self-esteem. It worked well with every task. At the beginning, we focused on relatively simple tasks, and gradually more complex tasks were addressed, such as planning a vacation, getting a job, engaging in a relationship, planning for her son's future, and finally her taking control of her obesity problem.

Time with the therapeutic coach started daily and then during the first 12 months was tapered down to three times a week. At the end of this period, time with the social worker began to be tapered from daily to three times a week. This gradual withdrawal of additional external supports was dosed in relation to Sonia's gains in self-control.

\section{The Second Phase, Years 2 to 4: From Victimhood to Job Holder, Addressing Distorted Interpersonal Thinking, Developing Financial Management Skills, and Working with Sonia's Mother}

\section{From Victimhood to Job Holder}

In the second phase, the therapeutic coach was restricted to helping with Sonia's specific target behaviors, such as starting courses in computer skills or knitting. Taking these courses was designed to help Sonia abandon her "victim" attitude in which she could only envy other people's capacities and gains, undermining her self-esteem and self-value. This was not a simple process and it involved very specific strategies. Because of her severe depression, Sonia was not motivated to do anything, but she also complained that everybody was active and successful (she was surrounded by doctors in her family who did very well professionally). She complained, viewing herself as a victim, and was passive in relation to her perceived plight. Paradoxically, 
The Case of "Sonia": Psychotherapy With a Complex, Difficult Patient Grounded

E. Scherb

Pragmatic Case Studies in Psychotherapy, http://pcsp.libraries.rutgers.edu

Volume 10, Module 1, Article 1, pp. 1-29, 03-21-14 [copyright by author]

she validated others' activity, showing that she believed that achievements in life were important, but that she did not believe she could accomplish them by herself. In the sessions, she was encouraged to find something that could demonstrate her personal value to others. Here's an example:

Sonia: Yesterday, I wanted to visit my brother, but he was busy with his patients, and the secretary would not let me in. How come a sister goes to visit her brother and he is never there for her? This is outrageous! They never loved me and they are always trying to avoid me, and then, they ask me to change and be nice. How can anybody be nice when one is rejected again and again?

Therapist: Can you picture yourself in reverse? What would happen if you were so busy that you could not open the door for your brother?

This would continue until she would build a mental image in which she would no longer be the victim, and from that standpoint, she could find a motivation to start doing things. Of course, this was a change of attitude that developed over time. Whenever Sonia mentioned something that she would like to do, the therapist would validate it, thereby reinforcing her initiative. For example, in the third year, Sonia found an opportunity to work in a government office. This job was not very promising at the beginning, but it was her first job in years. Despite this, her father discouraged her participation, saying that she would not be able to do it. The therapist encouraged Sonia to pursue the job, to encourage confidence in herself, and to give herself an opportunity to have a different future. She successfully applied for the job and began her work. During the first days of her job, she would wake up every morning and say, "I quit!" Nevertheless, every day that passed without quitting, we discussed how this was "one more day." After some months, Sonia started to earn money, and this gave her more confidence in herself, as well a greater sense of autonomy.

As of this writing, 10 years after the start of therapy, Sonia has been working in the government office for seven years. During the first two years, her family would say every other week that she should not work, and that she should instead focus on her medical treatment for obesity. Moreover, Sonia initially engaged in dysfunctional relationship patterns with her coworkers. However, she learned to identify cognitive distortions and control paranoid thoughts, as well as strategies to control and manage her exaggerated emotional reactions. Also, because she could experience the benefits of working and wanted to continue in the progress she was gaining, she applied what she learned.

Because of her vulnerable self-image, Sonia tended to abandon initiatives to improve her life. Despite these regressions, Sonia became stronger with every gain and more able to fight and overcome these setbacks. In the end, the gains were what motivated her to go on. In the therapy, these gains were validated and positively reinforced (e.g. by allowing Sonia to buy things and travel by herself). The following is an example of this process of reinforcing positive behaviors.

Sonia's parents owned a very pretty house on the beach. Sonia used to go there when she was a little girl and as she grew up she kept going with her parents to this house on vacations. But, as problems began to arise, and as her behavior became more and more aggressive, her 
The Case of "Sonia": Psychotherapy With a Complex, Difficult Patient Grounded

E. Scherb

Pragmatic Case Studies in Psychotherapy, http://pcsp.libraries.rutgers.edu

Volume 10, Module 1, Article 1, pp. 1-29, 03-21-14 [copyright by author]

parents were more and more reluctant to invite her to the house at the beach. When I first saw Sonia, she was not allowed to go to the house and had not been going for two years prior to starting treatment. This house was very meaningful for Sonia, because of her cherished memories from childhood,but in recent years staying in the house with her parents had become impossible. This was largely due to an incident involving Sonia's boyfriend, whom she had met on the street and had been seeing in a covert manner. Sonia's parents despised her boyfriend, who was also unemployed and had mental health problems. One night, Sonia's boyfriend came to the beach house and stood in the dark until dawn waiting for her to come out. When she didn't emerge, he started ringing the bell in the middle of the night, waking up all the neighbors, which was perceived as a very humiliating situation by her parents. From that point onwards, Sonia was excluded from the beach house, although her brother kept going there with his family on vacations. Sonia always wanted to again become a part of this family tradition. It was not until Sonia managed to fulfil her first year of work in her new job, improve her interpersonal skills, demonstrate her emotional regulation techniques, and save enough money to go to the beach that I negotiated with her mother to let Sonia come back to the beach house.

\section{Addressing Distorted Interpersonal Thinking}

In this phase of treatment, we also started working with Sonia's distorted thinking in session. For example, because of her underlying dysfunctional core belief of not being loved, she always interpreted others' behaviors with exaggerated feelings of abandonment and rejection, and behaved as if this belief needed to be confirmed with everyone. In this vein, whenever she could make a new friendship, she would test it to the extreme. On one occasion, she met a new partner in her workplace and started a friendship. Sonia would focus her attention on every little gesture and movement made by her new friend, in order to determine whether she was being accepted or not. If Sonia concluded that she was not being accepted, she would attempt to intensify her closeness to her new friend, rather than distance herself from her. Within the sessions, we worked to dismantle this mechanism in two ways:

1) Depersonalize: Sonia was encouraged to question whether it was accurate to assume that all the gestures and movements of the women she worked with were related to her.

2) Alternative Behavior: Instead of intensifying closeness in these occasions, Sonia was encouraged to try distancing herself from her peers. These strategies proved very useful for Sonia because she could rehearse the alternative behavior and then check the results in real time. For this purpose, we also had conjoint sessions with the therapeutic coach in which the coach and I analyzed Sonia's behaviors and proposed alternative behaviors within the session, which Sonia would then practice outside of session.

A motivation for Sonia to practice these alternative behaviors was the fact that she realized that if she was able to interpret others' behaviors in less negative ways, she would also be able to relate to them in other ways. The result of these changes was in her benefit. For example, when she started to work, she would say every other day that she would quit because of her strong tendency to negatively interpret the behavior of others. One example of a very frequent dialogue in session during those days follows: 
The Case of "Sonia": Psychotherapy With a Complex, Difficult Patient Grounded

E. Scherb

Pragmatic Case Studies in Psychotherapy, http://pcsp.libraries.rutgers.edu

Volume 10, Module 1, Article 1, pp. 1-29, 03-21-14 [copyright by author]

Sonia: Yesterday people stared at me in a funny way. I want to quit. Why should I go to a place where people are staring at me in that way?

Therapist: Why do you think they are staring at you in that way? Aren't they busy with work?

Sonia: Because I am obese, and I don’t care if they don’t like it; this is the way I am.

Therapist: And why would this in any way stop you from work, if you wanted so badly to be able to earn money and be like everybody else?

Sonia: That is true.

Therapist: So, if you are the one who wants to achieve this goal, in what way does abandoning your own goal benefit you?

Sonia: You are right...in no way at all, but that is the way it is, I always have the worst part.

Therapist: As you can see, it also depends on what you do to have the worst part, for instance, if you choose to quit, you are excluding yourself from an opportunity you yourself gained.

In this phase of treatment, Sonia was very determined that she did not want to change her body because she wanted "people to accept me the way I am." This idea was validated in treatment.

\section{Developing Financial Management Skills}

At this point, we also embarked upon a specific training program with Sonia in order to address her financial issues. After she earned her initial salary, she would establish one goal by herself (e.g., replacing the refrigerator), and her mother would not stop her financial support. She started to save and buy at the same time. This continued until she saved enough money to make a trip, and then it started all over again. The mother also complied with this program because this was much better that the previous uncontrolled spending. It also proved to Sonia and her mother that she had the necessary math skills.

\section{Working with Sonia's Mother}

During the first two phases in treatment, I had regular individual sessions with Sonia's mother every two weeks. In these sessions, I educated and guided her mother to think about her daughter in a more positive way. This also included specific instructions on how to behave towards Sonia. For example, I taught her mother that no matter what the issue was about, she should never continue a conversation when Sonia started to react with exaggerated emotion. If this happened, her mother had to postpone the conversation until Sonia calmed down, even if this would only happen after many days. I also taught her mother to think of Sonia's deregulated states (e.g., shouting and/or crying and/or verbally aggressive) as moments that would pass like the rain. This metaphor proved to be useful because one of the key issues regarding the dysfunctional communication pattern in the family was the overly catastrophic way Sonia's 
The Case of "Sonia": Psychotherapy With a Complex, Difficult Patient Grounded

E. Scherb

Pragmatic Case Studies in Psychotherapy, http://pcsp.libraries.rutgers.edu

Volume 10, Module 1, Article 1, pp. 1-29, 03-21-14 [copyright by author]

relatives interpreted her behaviors. Very gradually, as soon as they learned to respond in another manner to Sonia's outbursts, these outbursts started to be less and less frequent. This meant that Sonia was starting to gain control over her behaviors, and this allowed us to gradually decrease the directedness of our interventions.

\section{$\underline{\text { Consolidating Functional Gains }}$}

As a result of the first two phases of treatment, Sonia was able to rise from bed every day and fulfill an activity schedule; begin simple training courses (such as knitting and computer skills); maintain her own home with the therapeutic coach or social worker; manage her monthly expenses; abstain from previous aggressive or violent outbursts in public; maintain relationships for longer periods of time; make plans to engage in larger activities independently; and take medication correctly. In addition, she began planning to move to a new home, participate in a nutrition care program, and build new friendships.

\section{Third Phase, Years 4 to 6: Moving Sonia's Son to an Institution}

In the third phase of treatment, Sonia started her own life projects without the therapeutic coach. She was able to begin work at a new job and manage her own budget. However, another big problem emerged: Sonia's son was no longer a child, and the special schools would no longer take him. Living together with her son now turned into a domestic violence problem for Sonia. She would escalate into violent shouting and screaming whenever they had an argument and the child would react aggressively, asserting that he was not a child any more.

In the past, Sonia had rejected the option of putting her son into an institution. She would say, "I will not allow anyone to do to my child what they did to me." This child, however, was mentally retarded, and we found no other way to assist him other than to place him in an adequate institution. This was a very long process, and also included issues involving third parties. Historically, the only referral possible in Argentina for this type of problem was a psychiatric institution. Neither Sonia nor her son considered this to be an appropriate option. In the meantime, a new mental health law was passed, and the social security companies were obliged to provide mentally retarded patients with a proper institution (i.e. not the existing psychiatric ones) that included day care activities such as occupational therapy, a gym, crafts, agriculture, and so forth. The family sued the social security authorities and won the right for a proper institution for Sonia's son. However, at this time, Sonia was still arguing against outside placement, saying, "I will not do to my son what they did to me."

We decided to implement a new strategy to enable Sonia and her whole family to go on with their lives. A decision was made in terms of which was the most appropriate treatment for Sonia and her son. We knew that they could no longer live together in the same apartment. This was the most difficult moment in Sonia's treatment. Sonia's vulnerable sense of self made it difficult to be a mature mother. She could pamper her son, feed him, even nurture him with affection, but she could not fully accept his condition, or the fact that no matter how she would like things to be, they were not that way. Therefore, she had to accept a number of difficult realities: that her son was substantially impaired, that she could not take care of him alone, that 
The Case of "Sonia": Psychotherapy With a Complex, Difficult Patient Grounded

E. Scherb

Pragmatic Case Studies in Psychotherapy, http://pcsp.libraries.rutgers.edu

Volume 10, Module 1, Article 1, pp. 1-29, 03-21-14 [copyright by author]

she needed her family's help, and that an institution would be a better place for him to live than their own home. We started to work with the idea that "maybe the things that are good for me are not good for my son." One day, the police came to her door and said that her son was lying in the street after being beaten. This was the limit, and the strategy of moving Sonia's son to an institution was initiated. Sonia's family was asked to arrange everything for moving the boy, and Sonia was left no choice but to accept the cirumstances. The situation became very tense and nearly everything we had achieved was put at stake, but Sonia never abandoned her job during this phase.

This process was tough and did not always go smoothly. It involved changes in setting and integrating resources. These included:

1) Several family sessions, mostly without Sonia.

2) Visits to the institution, always with Sonia.

3) Alliance ruptures and resolutions.

Because of her vulnerable sense of self, at first Sonia interpreted the institutionalization of her son as her "failure," and as another rejection of her family and lack of recognition and validation of herself as a person. The pivotal anchoring idea to achieve change and cognitive restructuring was Sonia's conceptualization of motherhood. At a conscious level, Sonia wanted to be a good mother. In the beginning, I worked in a paradoxical manner in the sessions, asking her whether she could visualize situations in which a mother had to make choices between what is best for her versus what is best for her son. For example, when a child is leaving childhood to achieve adulthood, maybe mother would prefer him to stay at home, but that would not be the best for the growing child. Maybe the mother would prefer the child to go with her on vacations, but the child would prefer the contrary.

We worked with different types of psychoeducational examples, taking into account that Sonia had to learn to be the mother of a grown-up child, yet her parents had not fostered her autonomy in a functional way. Thus, focalizing development and growth, and not the loss and the abandonment, she started to accept this evolution in their lives.

At first, Sonia accepted that her son would be taken to the institution, but she would not agree to visit him. She demanded that the child should be brought home whenever she wanted. Because those were not the rules of the institution, at first they ordered that the mother should only visit her son once a month. This directive was not well accepted by Sonia, and she would try to play the "victim," demanding her son to be brought back home, and even threatening the whole team with legal action. In those occasions, I would reinforce her criteria of being a good mother, encouraging her to do whatever she thought was best for the child, not best for her, even if she thought that what was best was to sue. Gradually, as she confirmed that her son was more and more balanced, well educated, and calm when she saw him, she gained acceptance and started to visit the institution. At first we went together, and then Sonia went by herself. Every time she came home from visiting her son, we would focus on his gains and her gains as a mother of a grown-up child with mild mental retardation. In a cumulative way, the positive 
The Case of "Sonia": Psychotherapy With a Complex, Difficult Patient Grounded

E. Scherb

Pragmatic Case Studies in Psychotherapy, http://pcsp.libraries.rutgers.edu

Volume 10, Module 1, Article 1, pp. 1-29, 03-21-14 [copyright by author]

effects of acceptance and forgiveness started showing up, and Sonia became an ally of the institution, all of which improved her relationship with her family.

\section{Fourth Phase, Years 6 to 8: Further Consolidation of Functional Gains, Addressing Sonia's Obesity}

\section{$\underline{\text { Consolidating Sonia's Functional Gains }}$}

The fourth phase consisted of the consolidation of Sonia's gains. Treatment in this phase involved maintaining Sonia's progress with monthly individual psychotherapy sessions with Sonia and bi-monthly telephone conversations with her mother. Sonia had maintained her job and started to enjoy her relationship with her son, who now lived in a nearby managed community. She started to see that her son was happier, that he enjoyed his activities in the institution, and his relationship with his peers. Gradually, Sonia was allowed to visit her son in the community, and later on, to bring him home for short periods.

Sonia ultimately recognized that this move enabled her and her son to have their own lives, in which their individual impairments were not necessarily an impediment for each to find a meaningful lifestyle. Sonia perceived this improvement in her level of freedom and selfresponsibility as empowering rather than threatening.

Sonia's son's placement into a specialized program for adults with mental retardation also had a beneficial effect on her relationship with her mother, which gradually became less enmeshed. This reduction in pathological co-dependency led to the amelioration of aggression and violence between Sonia and her mother, as well as within the entire family. This was achieved because everyone learned to validate each other's gains and activities. This includes social context, in which, as soon as they found an adequate place for Sonia's son, it was interpreted as social acceptance of his mental condition. This helped them also to understand Sonia's problems, which were different from those of her son.

The family members' acceptance and validation of each others' failures and achievements helped change communication patterns among them. This change in turn had an impact on Sonia's core belief of not being loved, which had triggered her emotional dysregulation problems and, consequently, her perceived hatred towards her relatives. This meant that she was starting to build a positive self-concept with positive self-esteem. Only then could Sonia start to think in a positive manner on the possibility of looking after her physical health.

The turning point was the moment Sonia started to accept in a positive manner the collaboration and help of her family, which in turn led her family to help her in a better way. In the final phase, she was able to engage in long conversations with her father. At first, they started only over the phone, but over time it progressed to in-person, face-to-face interaction. Sonia's achievements led her to accept herself and consequently, to accept her significant others. This is most impressive with her father, who is an extremely rigid man who has had severe interpersonal difficulties with significant others. For example, as a family anecdote, Sonia's mother used to tell me that her husband never went to birthdays or family reunions when the children were little. After treatment, Sonia could start to understand that her father's difficulties, 
The Case of "Sonia": Psychotherapy With a Complex, Difficult Patient Grounded

E. Scherb

Pragmatic Case Studies in Psychotherapy, http://pcsp.libraries.rutgers.edu

Volume 10, Module 1, Article 1, pp. 1-29, 03-21-14 [copyright by author]

which had hurt her so much, had created substantial limitations in his own life. This realization helped Sonia - not in the sense of forgiving him, but in the sense of being able to think about what was best for her, and not only how she might take revenge on her father. Her thinking was no longer, "if he wants to see me thin, I will remain obese," and so on. Thus, reconciliation between father and daughter only started when Sonia achieved a level of self-appreciation and self-worth, which led her to think of what is best for her, such as trying to gain health and prevent all the illnesses that were starting to pop up as a result of her obesity.

\section{Addressing Sonia's Obesity}

In line with her reconciliation with her father and the reduction of her need to stay obese to spite her father, as another sign of progress, starting during the eighth year of treatment, Sonia began medical treatment for her obesity. First, she started visiting different obesity treatment programs and institutions. When she came to the sessions, we discussed them together. This was considered the final point in treatment because it revealed a change in dysfunctional core cognitive structures. This meant that Sonia was starting to accept herself, strive to care for herself, and be her own first priority. When she started treatment, she perceived her parents desire for her to reduce her weight as another way in which they expressed their rejection and lack of acceptance and love for her. But towards the end of treatment her acceptance came from inside, revealing how much she enabled herself to improve and attempt to fight for a better life.

\section{Fifth Phase, Years 8-10: Maintenance Sessions}

After formal discharge at year eight, we held maintenance sessions for two additional years, to monitor Sonia's gains and to employ relapse prevention strategies where needed. During this time the level of emotional, cognitive, and behavioral functioning that Sonia had achieved in years 1-8 was sustained. Also during this time Sonia underwent successful gastric bypass surgery and lost 132 pounds (60 kilograms), going from weighing 287 pounds (130 kilos) to weighing 132 pounds (60 kilos) over a period of 12 months. (One should note that Sonia's height is 5 feet.) As of this writing, this weight loss had been sustained for a period of 24 months.

\section{THERAPY MONITORING AND USE OF FEEDBACK INFORMATION}

As mentioned above, Sonia's case was conducted by a team of professionals, and this team met regularly to monitor her case and provide feedback for making adjustments in the course of the therapy.

As also mentioned above, because of her long history of previous treatments, Sonia did not consent to take any standardized assessment measures. However, she willingly agreed to audio and video recording of the sessions and to periodically complete an individualized List of Problems and Behaviors Questionnaire (LOPBQ), as shown in Table 2. The recordings were very helpful in team supervision sessions, and the periodic LOPBQ ratings were valuable in monitoring Sonia's progress over the years. The specific results on this measure will be discussed in the outcome section below. 
The Case of "Sonia": Psychotherapy With a Complex, Difficult Patient Grounded

E. Scherb

Pragmatic Case Studies in Psychotherapy, http://pcsp.libraries.rutgers.edu

Volume 10, Module 1, Article 1, pp. 1-29, 03-21-14 [copyright by author]

\section{CONCLUDING EVALUATION OF THE THERAPY'S PROCESS AND OUTCOME}

\section{Quantitative Results}

As just described, Sonia periodically completed an individualized List of Problems and Behaviors Questionnaire (LOPBQ). The form itself is presented in Table 2. The LOPBQ consists of 27 items that Sonia and her therapist had "built together" early in therapy. Each item describes a particular problem of Sonia's and was rated by Sonia along a scale from " $0=\mathrm{I}$ have not solved this problem at all, it is getting worse," to " $5=$ I have totally solved this problem, it no longer exist for me." This resulted in a potential range of scores of 0 to 135.

Table 3 shows the results on each item at 6 points across the 8 years of therapy. Over the course of therapy these scores increased progressively and dramatically. Specifically, the average score per item started at .33 and increased to 4.19, while the total score started at 9 and increased to 113 . In other words, Sonia went from $6.7 \%$ of a maximum score to $83.8 \%$ of a maximum score over the 10 years of therapy.

\section{Qualitative Results}

Paralleling the quantitative results in Table 3, the description above in the Course of Therapy section documents the gradual but strikingly positive and sustained changes in Sonia's mood and functioning over the 10 years of therapy.

A follow-up interview was conducted at the end of year 10. Sonia was in very good shape, maintaining her 60 kilos weight loss. She had also undergone hip surgery during the past year (a consequence of her previous overweight condition), and had recovered fully from this operation. She showed and expressed lots of gratitude towards me and towards treatment. She was maintaining her job. In addition, she had a very good relationship with the institution where her son was living and she was enjoying the gains he had made. Her son continued visiting her every two weeks, and she even made jokes about their mutual joy whenever the taxi blows his horn to take her son back to the institution. She says, "We both feel happy with the horn! Two days and one night together is enough!"

Sonia's relationship with her brother was fine, and at work Sonia said that she very much appreciated having some new good friends. She had even ended the sexually abusive relationship with her old boyfriend, and could now view him as a very old acquaintance with whom she is no longer intimate. In our interview, Sonia was wearing elegant and stylish clothes, and she told me that she so much enjoyed finding that whenever she put on a new outfit, it looked very attractive on her.

The only problem that came up in the interview concerned the fact that Sonia wants to make a trip to New York City (she has never been abroad) and she asked her parents for the money, but they resisted. Her father once had made Sonia a promise that she could go to New York City when she became thin. Now she was thin, but they said she was not capable of 
The Case of "Sonia": Psychotherapy With a Complex, Difficult Patient Grounded

E. Scherb

Pragmatic Case Studies in Psychotherapy, http://pcsp.libraries.rutgers.edu

Volume 10, Module 1, Article 1, pp. 1-29, 03-21-14 [copyright by author]

traveling. It seemed as though there was therapeutic work to be done with Sonia and her family around this issue.

After I saw Sonia, the relationship issues with her mother came up again, and it became apparent to me that traveling to New York City was not the issue. The discussions between Sonia and her mother, the repetitive phone calls, and the mutual recriminations between them came back, only in a very less intense manner compared to earlier times. The relationship issues were only with her mother, while Sonia's other relationships were in good health. I decided to address this problem as before. I gave Sonia an assignment: to go get a Visa to travel to the USA. The message was: "You can do it, but you have to find the way to do it yourself." Until that point, she had never gone to the USA Embassy.

It became apparent that the problem for her was to understand, once again, how much she can expect from the love and acceptance of others, and how much she can achieve it by herself. Even with a new body, the old patterns (core meaning structures) could return. The difference was that now she has not only insight, but lots of resources that she herself gained with her own effort, and which she can use to face a crisis. After our last session, she had stopped the phone calls and recriminations and was now focused on getting on with her life.

\section{Conclusion}

In Sonia's case, the over-protective attitudes of the family masked their profound rejection of Sonia and her son because of the social stigma of mental retardation, as well as Sonia's severe functional limitations and difficulties and her biologically based tendency to be overly emotional. The use of validation (Linehan, 1993), confirmation, genuine social support, and encouragement of a gradual nature increased Sonia's ability to take responsibility for her actions. Intensive skills training and the practice of interpersonal skills also proved to be helpful. Some of the cognitive and behavioral skills Sonia learned included coping when someone does not respond the way in which you expected him or her to; accepting that not everybody is obliged to love you; and understanding and controlling emotional dysregulation. Other types of skills involved learning to control spending and everyday life organization, mainly with tokeneconomy-based techniques. All of this skill training helped Sonia to go on with her life.

In addition to developing adaptive skills, a crucial part of the therapy was working with Sonia's distorted thinking in session. For example, as mentioned above, Sonia's underlying dysfunctional core belief of not being loved led her to interpret others' behaviors - both family and non-family acquaintances - with exaggerated feelings of abandonment and rejection, and behave as if this belief needed to be tested with everyone she dealt with. Within the sessions, we worked to dismantle this mechanism in two ways: by making Sonia aware that others were not intensely focused just on her, and by practicing alternative behaviors with others to emotionally defuse them.

As mentioned above, an important turning point was the moment Sonia started to accept in a positive manner the collaboration and help of her family, and consequently, her family helped her in a better way. This was accompanied by a rapprochement with her father. Up to that 
The Case of "Sonia": Psychotherapy With a Complex, Difficult Patient Grounded

E. Scherb

Pragmatic Case Studies in Psychotherapy, http://pcsp. libraries.rutgers.edu

Volume 10, Module 1, Article 1, pp. 1-29, 03-21-14 [copyright by author]

point Sonia had refused to take any action on her obesity in order to spite her father. This was self-destructive not only to Sonia's health but also to her self-image. The rapprochement allowed her to reverse this process and obtain a successful gastric bypass surgery, which greatly lifted her self-esteem.

After nearly 900 sessions over 10 years of at first intensive and then maintenance psychotherapy, combined with maintenance medication, Sonia now maintains a life of relative autonomy. She has continued to remain at an appropriate weight and to live a healthy lifestyle. She has been working continuously for the last three years; manages her own personal finances and home; has good working relationships with her son and family; has developed some friends through work; and has continued accepting the termination of her previous sexually abusive relationship. Moreover, she has broken the cycle of psychiatric hospitalizations and has not been hospitalized in the past 10 years. All this change and growth has been deeply satisfying both for Sonia and for me in my role as Sonia's therapist! 
The Case of "Sonia": Psychotherapy With a Complex, Difficult Patient Grounded

\section{REFERENCES}

Duncan, B., \& Miller, H. \& Hubble, M. (1997). Psychotherapy with impossible cases: The efficient treatment of therapy veterans. New York: W. W. Norton \& Company.

Fernández-Álvarez, H. (1992). Fundamentos de un Modelo Integrativo. Buenos Aires: Paidos.

Fernández-Álvarez, H. (2001). Fundamentals of an integrated model of psychotherapy. New York: Guilford.

Fernández-Álvarez, H., Fernando S. Garcia, F. S., \& Scherb, E. (1998). The research program at AIGLE. Journal of Clinical Psychology, 54, 343-359.

Koerner, K. (2011). Dialectical Behavior Therapy: A practical guide. New York: Guilford.

Linehan, M. (1993). Cognitive behavioral treatment for personality disorders. New York: Guilford.

Persons, J. B. (2008). The case formulation approach to cognitive-behavior therapy. New York, Guilford.

Perris, C. (1999). A conceptualization of personality-related disorders of interpersonal behaviour with implications for treatment. Clinical Psychology \& Psychotherapy , 239-260.

Scherb, E. (2003). Investigacion y Psicoterapia: Pacientes dificiles, un enfoque desde la intersubjetividad. [Psychotherpy research with difficult patients: An intersubjective approach.] Subjetividad y Procesos Cognitivos, 220-242.

Scherb, E. (2007a). Las psicoterapias en el tratamiento de pacientes con características diagnósticas que revisten severidad y complejidad: abordajes innovadores que permiten optimizar sus resultados [The psychotherapeutic treatment of patients with diagnostic features that are severe and complex: Innovative approaches to optimize results.] Doctoral Dissertation, Universidad del Salvador, Buenos Aires, Argentina.

Scherb, E. (2007b). Assessing improvement in patients with severe and complex diagnostic characteristics treated with the Cognitive Integrated Model: A naturalistic, longitudinal rsearch project. Paper presented at the annual meeting of the International Society for Psychotherapy Research, Madison, WI.

Scherb, E. (2011) The relevance of metacognitive aspects in the psychotherapy process with difficult patients. Paper presented at the annual meeting of the International Society for Psychotherapy Research, Bern, Switzerland.

Scherb, E. (2012). Following up nuclear schemas in difficult patients. Paper presented at the annual meeting of the International Society for Psychotherapy Research, Virginia Beach, VI.

Wachtel, P. (1997). Psychoanalysis, behavior therapy and the relational world. New York: City University of New York. 
The Case of "Sonia": Psychotherapy With a Complex, Difficult Patient Grounded

E. Scherb

Pragmatic Case Studies in Psychotherapy, http://pcsp.libraries.rutgers.edu

Volume 10, Module 1, Article 1, pp. 1-29, 03-21-14 [copyright by author]

Table 1. Sonia’s Treatment Phases, Treatment Resources and Frequency Over Time

\begin{tabular}{|c|c|c|c|c|c|}
\hline \multirow[b]{2}{*}{$\begin{array}{l}\text { TREATMENT } \\
\text { RESOURCES }\end{array}$} & \multicolumn{5}{|c|}{ TREATMENT PHASES AN MAINTENANCE PHASE } \\
\hline & $\begin{array}{l}\text { First Phase, } \\
\text { Year } 1\end{array}$ & $\begin{array}{l}\text { Second } \\
\text { Phase, } \\
\text { Years 2-4 }\end{array}$ & $\begin{array}{l}\text { Third Phase, } \\
\text { Years 4-6 }\end{array}$ & $\begin{array}{l}\text { Fourth Phase, } \\
\text { Years 6-8 }\end{array}$ & $\begin{array}{l}\text { Maintenance } \\
\text { Phase, Years } \\
8-10\end{array}$ \\
\hline Psychotherapy sessions & $\begin{array}{l}\text { Three times } \\
\text { a week }\end{array}$ & $\begin{array}{l}\text { Two times } \\
\text { a week }\end{array}$ & Once a week & $\begin{array}{l}\text { Every two } \\
\text { weeks to } \\
\text { monthly }\end{array}$ & $\begin{array}{l}\text { Monthly to } \\
\text { every six } \\
\text { months }\end{array}$ \\
\hline $\begin{array}{l}\text { Family sessions with the } \\
\text { psychotherapist }\end{array}$ & $\begin{array}{l}\text { Every two } \\
\text { weeks }\end{array}$ & $\begin{array}{l}\text { Every two } \\
\text { weeks with } \\
\text { mother }\end{array}$ & $\begin{array}{l}\text { Once a } \\
\text { month with } \\
\text { mother. } \\
\text { Eventually } \\
\text { with brother } \\
\text { and sister- } \\
\text { in-law. }\end{array}$ & $\begin{array}{l}\text { Once with the } \\
\text { whole family }\end{array}$ & Once a year \\
\hline Social worker at home & Daily & $\begin{array}{l}\text { Three times } \\
\text { a week }\end{array}$ & ------------- & --------------' & ------- \\
\hline $\begin{array}{l}\text { Therapeutic coach } \\
\text { coordinated with the } \\
\text { psychotherapist }\end{array}$ & $\begin{array}{l}\text { Three times } \\
\text { a week }\end{array}$ & $\begin{array}{l}\text { Once a } \\
\text { week to } \\
\text { once every } \\
\text { two weeks }\end{array}$ & --------------- & --------------- & $\begin{array}{ll}------ \\
\end{array}$ \\
\hline $\begin{array}{l}\text { Telephone sessions with } \\
\text { the psychotherapist }\end{array}$ & $\begin{array}{l}\text { Daily or } \\
\text { every other } \\
\text { day }\end{array}$ & $\begin{array}{l}\text { Three times } \\
\text { a week }\end{array}$ & $\begin{array}{l}\text { Once a } \\
\text { month }\end{array}$ & Occasionally & Occasionally \\
\hline $\begin{array}{l}\text { Visits to institutions/ } \\
\text { organizations with the } \\
\text { psychotherapist }\end{array}$ & $\begin{array}{l}\text { Once, to the } \\
\text { son's special } \\
\text { needs } \\
\text { school }\end{array}$ & $\begin{array}{l}\text { Twice, to } \\
\text { her work } \\
\text { place }\end{array}$ & $\begin{array}{l}\text { Three times } \\
\text { to the } \\
\text { institution } \\
\text { where her } \\
\text { son was } \\
\text { living }\end{array}$ & --------------------- & -------- \\
\hline $\begin{array}{l}\text { Visits to medical doctors } \\
\text { with the psychotherapist }\end{array}$ & $\begin{array}{l}\text { Twice, to } \\
\text { her son's } \\
\text { medical } \\
\text { doctor }\end{array}$ & \begin{tabular}{|l}
-------------- \\
\end{tabular} & -------------- & ------------------- & 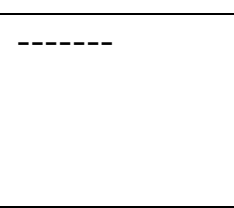 \\
\hline
\end{tabular}




\section{$\underline{\text { Table 2. Items on the List of Problems and Behaviors Questionnaire (LOPBQ) }}$}

This is the list of problems we built together.

Please rate how much you feel you have solved each of them in the last few weeks.

Rate from 0 to 5 , where 0 means the problem remains totally unsolved, and 5 means the problem is solved.

$0=\mathrm{I}$ have not solved this problem at all.

$5=\mathrm{I}$ have totally solved this problem, it no longer exist for me.

A. Financial

B. Work

C. Loneliness

— D. Separation issues

_ E. Physical problems

_ F. Stigmatization

_ G. Daily Organization

- H. Occupational

_ I. Low self-esteem

_ J. Assertiveness

— K. Powerlessness

_ L. Poor self-concept

_ M. Learned helplessness

- N. Anxiety

_ O. Depression

_ P. Conflict with others

- Q. Obessive indiscriminate anger

_ R. Excessive anger

_ S. Isolation

_ T. Hopelessness

_ U. Procastination

— V. Cognitive deficits

— W. Bizarre behaviors

_ X. Self destructiveness

_ Y. Impulsivity

_ Z. Culpability

_ AA. Thought disorders 
The Case of "Sonia": Psychotherapy With a Complex, Difficult Patient Grounded

Pragmatic Case Studies in Psychotherapy, http://pcsp.libraries.rutgers.edu

Volume 10, Module 1, Article 1, pp. 1-29, 03-21-14 [copyright by author]

Table 3. Results on the LOPBQ

\begin{tabular}{|c|c|c|c|c|c|c|}
\hline \multicolumn{7}{|c|}{ Time of Assessment } \\
\hline Sonia's List of Problems & $\begin{array}{r}\text { At } \\
6 \text { months } \\
\end{array}$ & $\begin{array}{r}\text { At } \\
12 \text { months }\end{array}$ & $\begin{array}{r}\text { At } \\
18 \text { months }\end{array}$ & $\begin{array}{r}\text { At } \\
5 \text { years }\end{array}$ & $\begin{array}{r}\text { At } \\
6 \text { years } \\
\end{array}$ & $\begin{array}{r}\text { At } \\
8 \text { years }\end{array}$ \\
\hline _A. Financial & 1 & 2 & 2 & 4 & 5 & 5 \\
\hline _ B. Work & 0 & 0 & 0 & 2 & 5 & 5 \\
\hline _C. Loneliness & 1 & 1 & 2 & 2 & 3 & 3 \\
\hline D. Separation issues & 1 & 1 & 2 & 4 & 5 & 5 \\
\hline E. Physical problems & 1 & 1 & 1 & 1 & 1 & 4 \\
\hline F. Stigmatization & 1 & 1 & 2 & 4 & 5 & 4 \\
\hline _ G. Daily Organization & 0 & 1 & 2 & 4 & 5 & 4 \\
\hline _ H. Occupational & 0 & 0 & 0 & 4 & 5 & 4 \\
\hline I. Low self-esteem & 1 & 1 & 1 & 2 & 3 & 4 \\
\hline J. Assertiveness & 0 & 1 & 1 & 2 & 3 & 4 \\
\hline _ K. Powerlessness & 0 & 1 & 1 & 2 & 3 & 4 \\
\hline _ L. Poor self concept & 0 & 0 & 0 & 2 & 3 & 4 \\
\hline $\begin{array}{c}\text { M. Learned } \\
\text { helplessness }\end{array}$ & 0 & 1 & 1 & 2 & 3 & 4 \\
\hline N. Anxiety & 0 & 1 & 2 & 4 & 3 & 3 \\
\hline _ O. Depression & 0 & 1 & 2 & 4 & 5 & 4 \\
\hline _ P. Conflict with others & 0 & 0 & 1 & 2 & 3 & 3 \\
\hline $\begin{array}{l}\text { Q. Obsessive indiscrim- } \\
\text { inate anger }\end{array}$ & 0 & 0 & 0 & 3 & 4 & 5 \\
\hline _ R. Excessive anger & 0 & 0 & 0 & 3 & 4 & 5 \\
\hline _ S. Isolation & 1 & 1 & 0 & 2 & 4 & 4 \\
\hline — T. Hopelessness & 0 & 0 & 0 & 1 & 4 & 4 \\
\hline _ U. Procrastination & 0 & 0 & 2 & 3 & 4 & 3 \\
\hline _ V. Cognitive deficits & 2 & 2 & 2 & 3 & 4 & 4 \\
\hline _ W. Bizarre behaviors & 0 & 0 & 3 & 4 & 5 & 5 \\
\hline _ X. Self destructiveness & 0 & 0 & 3 & 4 & 4 & 5 \\
\hline _ Y. Impulsivity & 0 & 0 & 2 & 3 & 4 & 5 \\
\hline _ Z. Culpability & 0 & 0 & 2 & 3 & 4 & 5 \\
\hline _ AA. Thought disorders & 0 & 0 & 3 & 4 & 4 & 4 \\
\hline Total Score & 9 & 16 & 37 & 78 & 105 & 113 \\
\hline Average Score Per Item & 0.33 & 0.59 & 1.37 & 2.89 & 3.89 & 4.19 \\
\hline
\end{tabular}

Note: In the first half of treatment, the list was rated every 6 months because of Sonia's level of pathology. In the second half, as she improved, the list was rated every year or so. 